\title{
A COMPARATIVE STUDY ON THE HISTORIC LANDSCAPE OF OLD CITY KABUL
}

\author{
M. Umar Azizi ${ }^{1}$ \\ ${ }^{1}$ Graduate Student, Civil Engineering and Architecture Department University of the Ryukyus, Okinawa, Japan \\ moh.umar@hotmail.com
}

\begin{abstract}
The historic landscape of adobe houses in the old city of Kabul transformed from traditional to the newly industrialized after several decades of the wars. The maximum number of stories of the old houses in the past were two with a parapet wall, which currently has changed to the four-stories. As per the outcomes of the study, the majority of $72 \%$ of the residents reasoned their preference of industrialized material over natural to be an increasing number of family members along with the various advanced house functions. Moreover, in order to mitigate the on-going modernization pressure in the old city, some recommendations proposed.
\end{abstract}

Keywords: Old City of Kabul, Historic Landscape of Kabul, Conservation of Old City Kabul, Asheqan Wa Arefan

\section{INTRODUCTION}

The architectural remains confirm the existence of Buddhists settlements between $1^{\text {st }}$ and $5^{\text {th }}$ century $\mathrm{AD}$ in the old city of Kabul (Soave, 2007). Over the years, the ancient town extended to a village located in a defense area that was protected by nature and surrounded by Kabul River (Daryay-e-Kabul) to the north, Sher Darwaza Mountain to the south, Bala-Hissar Citadel to the east and Kabul Walls from south to the west.

The aftermath of the war left $80 \%$ of the old city destroyed (Zahra, 2004). After wars, many of the heritage building were ignored and no proper mechanism for their restoration was provided [3]. On the other hand, the legal ownership verification of the land in the old city became complicated for the government, and as a result, many new high-rise buildings are being built [4].

\subsection{Research Background and Objective}

The Ministry of Urban Development and Housing (MoUDH) has drawn a conservation zone covering the old city of Kabul (presently recognized as Shahr-e-Kohna and district 1) and part of the district 2 shown in Fig. 1[5].

The boundary for the conservation zone surround Asmayi mountain, Kabul River, Mandawi (markets), Bagh-e-Ali Mardan, Chindawol, Shur Bazar, Asheqan wa Arefan, Kuch-e-Kharabat, Sher Darwaza mountain and Bala-Hissar citadel.

A similar conservation border was clarified in the district 7 southwest of the old city, in order to protect Bagh Babur Garden. In 2002, the restoration process of the garden was initiated in a collaborative effort by Aga Khan Trust for Culture (AKTC) and Kabul Municipality (KM) [6].
According to the improper legal status of the houses after the wars in the old city, the district office issues a temporary permit of repair works to the respective owners on a condition that local materials used [7].

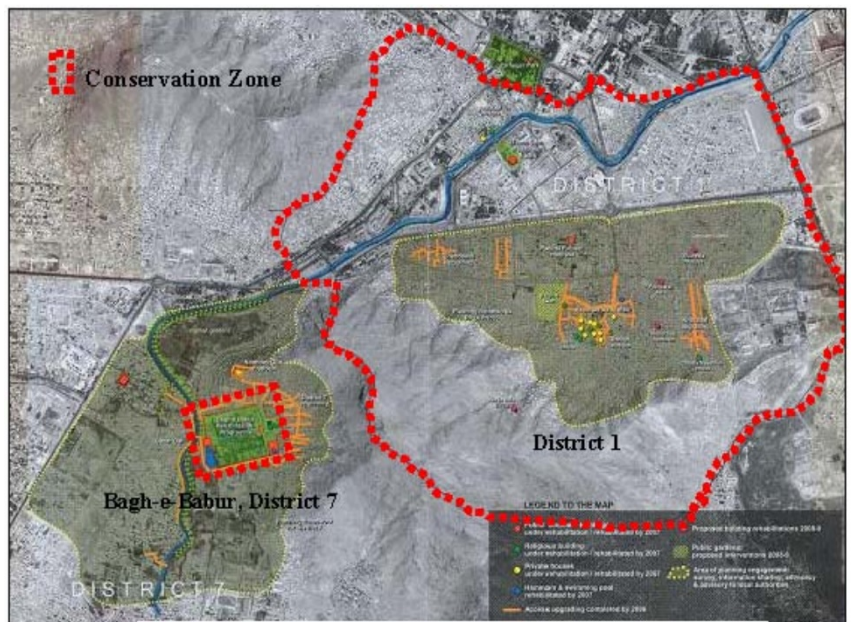

Fig. 1 The boundary of conservation zone (MoUDH)

This paper investigates the historic landscape of the old city of Kabul after the wars from modernization perspective focusing on the residential quarters that located in the conservation zone. The research also attempts to find the reasons behind industrialization of the houses based on the resident's interviews.

\section{RESEARCH METHODOLOGY}

\subsection{Governmental Records and Online Publications}

The secondary data was collected from Ministry of Urban Development and Housing (MoUDH), Kabul Municipality (KM) and Central Statistics Organization (CSO) for reviewing. 
Some online publications, articles, and books were also studied to compare the characteristics of the historic landscape of old city with the modern.

\subsection{Physical Appearance Observation}

The physical appearance of 60 houses was observed through a cluster sampling in the historical area of Asheqan wa Arefan and Chindawol. The observation was based on the pictures which were taken from the exterior side of the modern houses exposed to the alleys and public spaces.

\subsection{Questionnaires}

Face-to-face interviews of 54 modern house owners were also conducted based on the year of their construction and to acquire reasons for the use of industrialized materials.

\section{STUDY AREA}

The study area selected in the least damaged area during the wars (Azizi, 2016). The area situated between commercial part of Mandawi to the north, Sherdarwaza hillside squatter to the south, Shur Bazar quarter to the northeast, Kuch-eKharabat area to the southeast and Kabul river to the west (Fig. 2). The shrine of Asheqan wa Arefan is an important pilgrimage place and graves of the two brothers: Abdus Salam (Asheqan) and Abdus Samad (Arefan) located to the south area. The occupancy and construction of some old adobe houses in the study area has been estimated to be from the1860s (Toofan, 2012).

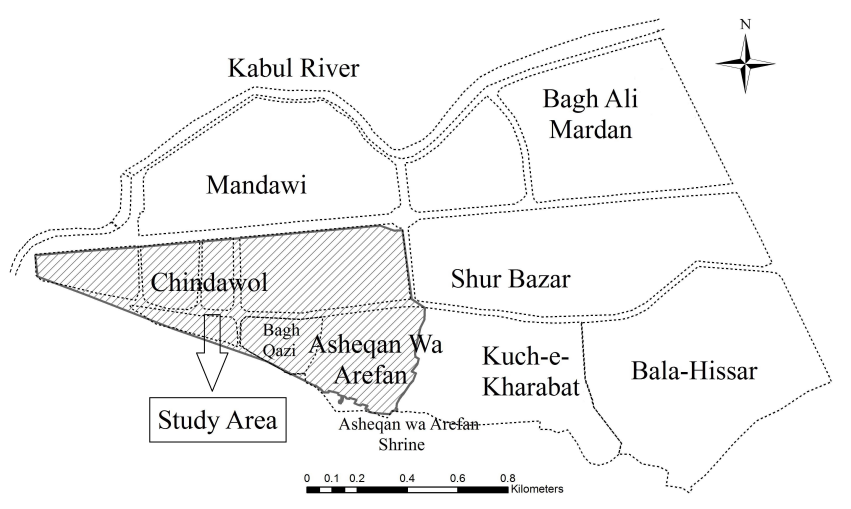

Fig. 2 Location of the study area

\section{DATA COLLECTION}

\subsection{The Physical Appearance Observation}

The details of the physical appearance of the 60 houses (6 old adobe houses and 54 modern) that was observed in the study area are shown in Table- 1 :

Table- 1 The 60 houses observed from alleyways and open spaces *W/P-With Parapet

\begin{tabular}{|l|l|l|l|l|l|l|}
\hline \multirow{2}{*}{$\begin{array}{l}\text { House } \\
\text { Type }\end{array}$} & \multicolumn{5}{|l|}{ Number of stories } & \multirow{2}{*}{ Total } \\
\cline { 2 - 6 } & 1 & 2 & $2 \mathrm{~W} / \mathrm{P}$ & 3 & 4 & \\
\hline Adobe & - & 6 & - & - & - & 6 \\
\hline Modern & 8 & 26 & 5 & 12 & 3 & 54 \\
\hline Total & 8 & 32 & 5 & 12 & 3 & 60 \\
\hline
\end{tabular}

\section{Definition of the Houses}

1. Old adobe type houses are the original historical houses constructed in the 1860s (Toofan, 2012). The walls are adobe locally known as (Dewar Sinji and Dewar Pakhsaye) covered by mud-straw plaster shown in Fig. 3 . The windows and doors are from wood (Patai) with many decorations on the top. On the upper roof, an adobe parapet walls covered by mud-straw built to use during hot summers for the purpose of sleeping in nights.

2. The modern type houses are the industrialized homes constructed after the wars shown in Fig. 4. The walls made of burned bricks whereas RCC/metallic beams used for the roofs. A cement plaster used as a covering layer of the burned bricks on the walls shown in Fig. 5. The windows are simple wooden, and the main door is metallic.

A common type of 32 houses was found to be two-story houses ( 6 old adobe types houses and 26 modern) ( Fig. 7). According to Fig. 6, the 26 modern houses which secure $48 \%$ of the total houses sampled were two-story whereas, only five houses account for $9 \%$ of the total house sampling were two-story dwellings with parapet walls shown in Fig. 4. In addition to this, one-story, three-story and four-story house numbers counted as $8(15 \%), 12(22 \%), 3(6 \%)$ respectively.

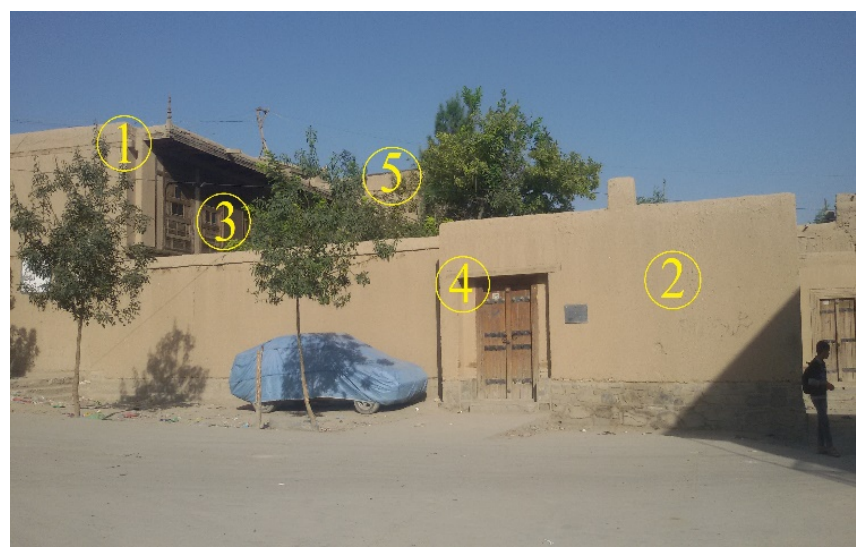

Fig. 3 An old traditional type adobe house *1-Dewar Sinji, 2-Mud straw plaster, 3-Window (Patai),4-Door, 5-Parapet wall

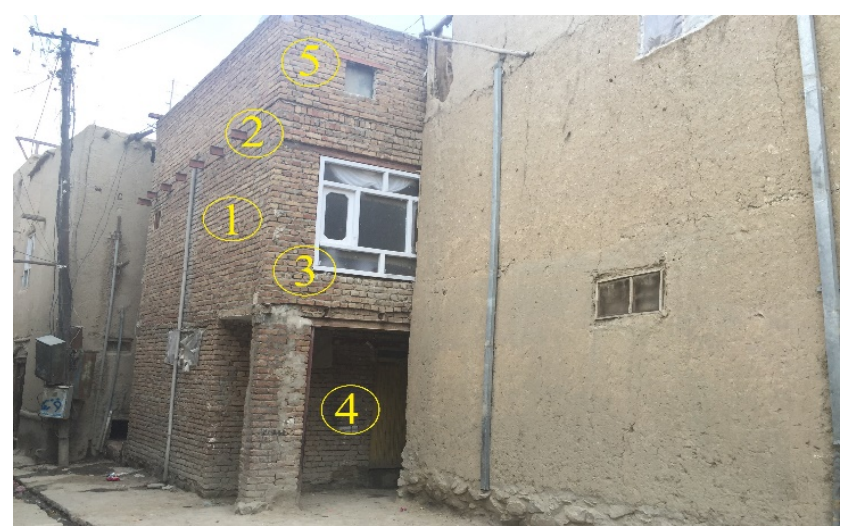

Fig. 4 A modern type house used baked bricks in the walls *1-Wall, 2-Metallic beam, 3-Window, 4- Door, 5-Parapet wall 


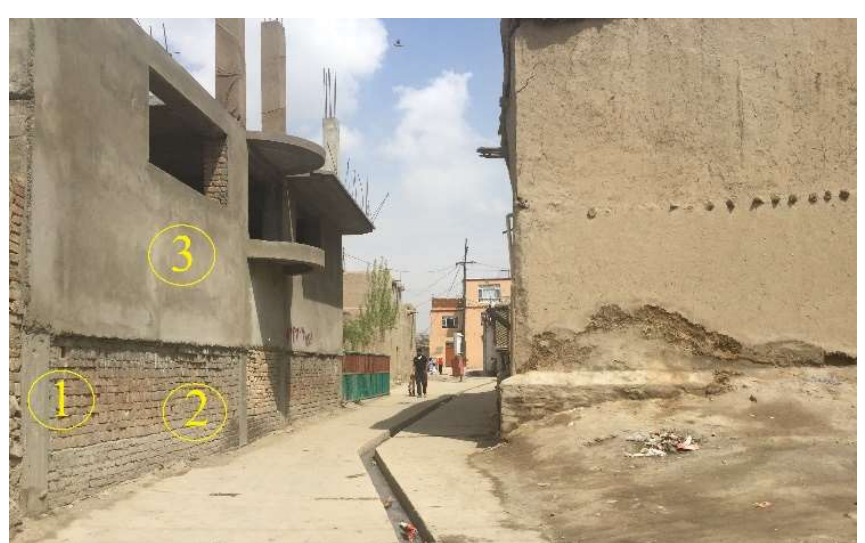

Fig. 5 A modern reinforced cement concrete (RCC) type house with the cement plaster used on the walls *1-RCC column, 2-Baked bricks wall, 3-Cement plaster

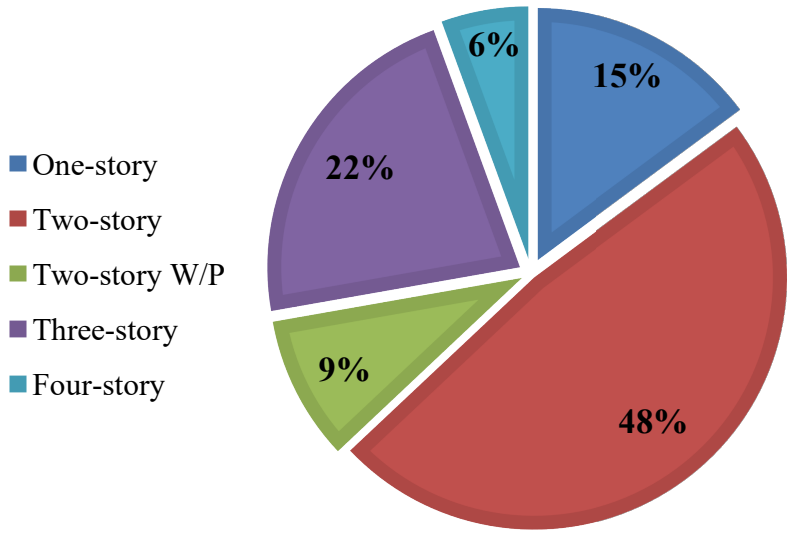

Fig. 6 The existence of four types modern houses according to the story *W/P-With parapet

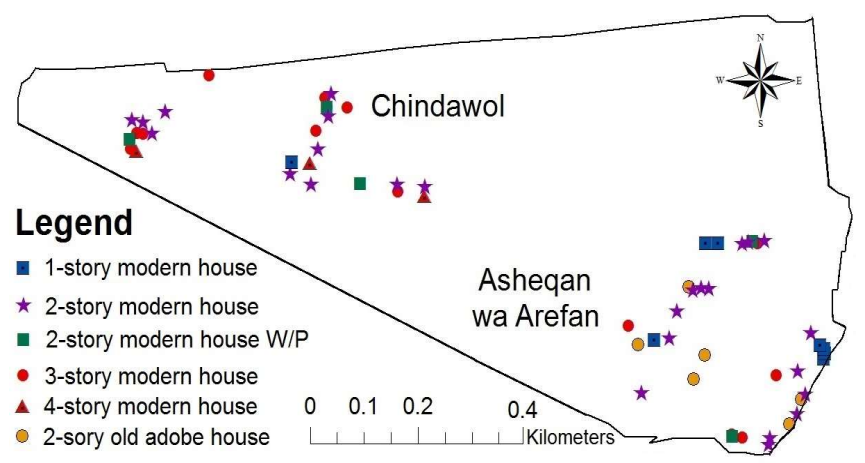

Fig. 7 The location of the houses by physical observation

\subsection{Survey Findings}

As per field survey with the residents, the construction process of the modern houses can be divided into the 2 periods based on the pressure of built:

1- First period (2002-2007)

2- Second period (2008-2015)

The graph of the Fig. 8 shows that $36(67 \%)$ of the modern houses, which are the majority in numbers, were constructed in the first period (2002-2007). However, the construction process hindered in the second period (2008-2015), and the number decreased to $18(33 \%)$.

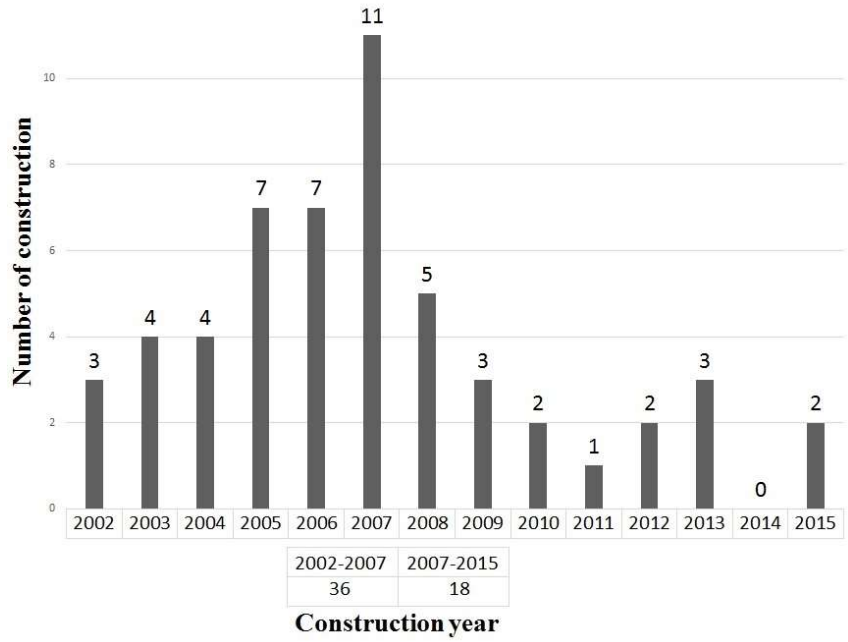

Fig. 8 A construction period of the modern houses by year

The residents have various reasons for the use of industrialized materials in their houses according to the survey shown Table- 2. The majority of the (houses) 27 houses were built as modern because of increasing number of family members. Whereas 12 habitats, being the second largest in numbers, constructed their homes from modern materials for the reason of advanced functions such as (modern kitchen and toilets). The 11 owners used technologically advanced materials for the purpose of the disasters prevention measures such as (earthquake and flood). The remaining four houses justified renting their home to other families.

Table- 2 The reason for the construction of modern houses * FM-Family members, AF-Advanced function, D-Disaster, R-Rent,

\begin{tabular}{|l|l|l|l|l|l|}
\hline \multirow{2}{*}{ Residents } & \multicolumn{3}{|l|}{ Reason } & \multirow{2}{*}{ Total } \\
\cline { 2 - 6 } & FM & AF & D & R & \\
\hline One-story & 4 & 2 & 2 & - & 8 \\
\hline Two-story & 10 & 7 & 6 & 3 & 26 \\
\hline Two-story WP & 3 & - & 2 & - & 5 \\
\hline Three-story & 8 & 2 & 1 & 1 & 12 \\
\hline Four-story & 2 & 1 & - & - & 3 \\
\hline Total & 27 & 12 & 11 & 4 & 54 \\
\hline
\end{tabular}

\section{COMPARISON OF THE OLD AND MODERN}

\section{LANDSCAPE}

According to Fig. 9, the characteristic of the old city of Kabul in the past just before the wars was one and two-story adobe houses with a parapet wall. The newly industrialized appearances of the houses have changed its landscape to the modern which are three and four-story houses as shown in Fig. 10. 


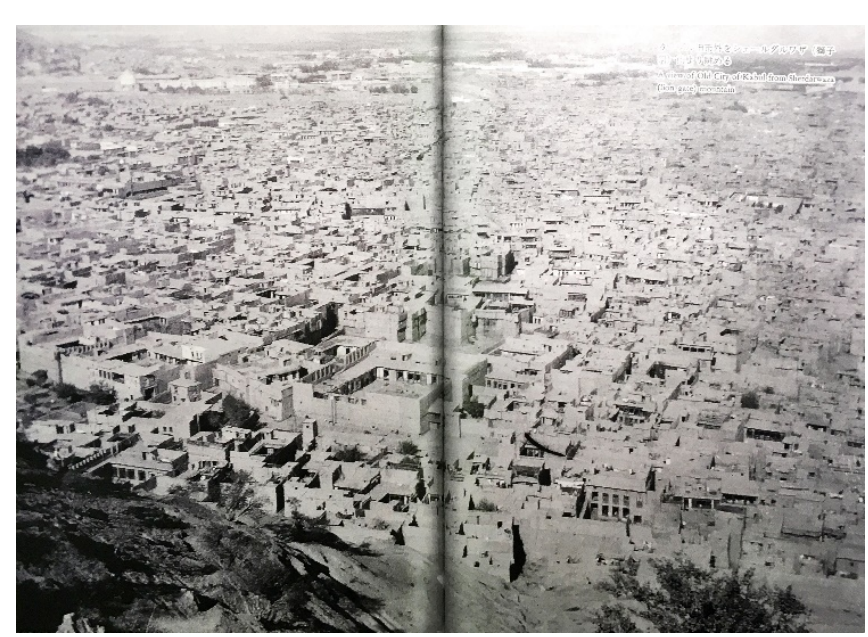

Fig. 9 A view of the old city Kabul in 1935 (尾崎三雄)

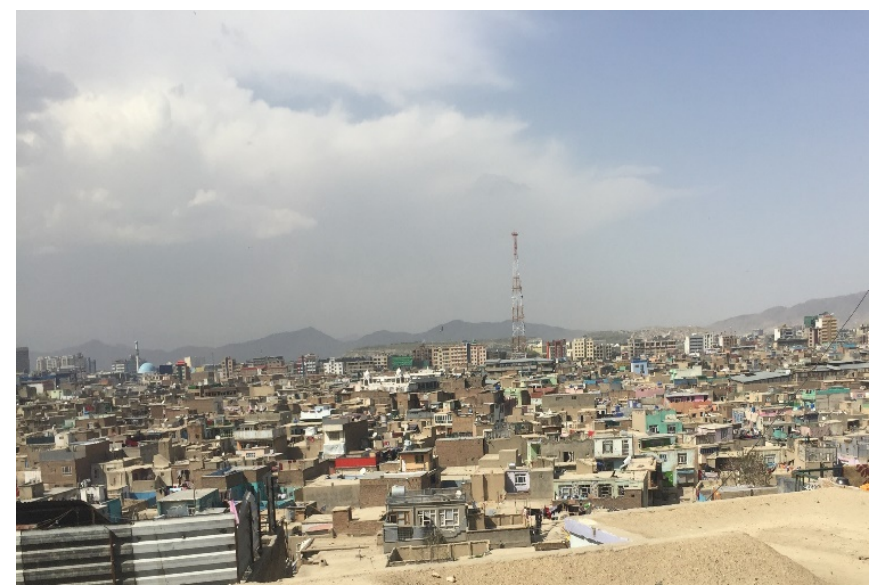

Fig. 10 A view of the old city in 2016 (Author's photo)

Table- 3 shows the comparison of the old adobe and modern industrialized houses in the old city of Kabul. The walls of the old houses were in Sinj (adobe bricks and wooden frames/mud and wooden frames), Pakhsa (mud) and unbaked bricks with mud. However, the mentioned traditional type walls dramatically changed in new houses to baked bricks shown in Fig. 4. The plaster on the wall of the old houses used to be mud-straw which, later on, -transformed to the cement in modern houses (Fig. 5). The window and door of the old houses were made of Patai (sliding timber shutters) with beautiful wooden decoration whereas a simple wooden window is used in modern homes and a metallic main door (Fig. 4).

Table- 3 Comparison of the old and modern houses *HT-House type, O-Old, MO-Modern, W-Wall, PL-Plaster, WI-Window, S-Sinj, P-Pakhsa, U-Unbaked bricks, B-Baked bricks, M-Mud straw, CCement, PA-Patai, OR-Ordinary, ME-Metallic, o-Yes, x-No

\begin{tabular}{|l|l|l|l|l|l|l|l|l|l|l|l|}
\hline \multirow{2}{*}{ HT } & \multicolumn{9}{|l|}{ House elements } \\
\cline { 2 - 12 } & \multicolumn{1}{l|}{ W } & \multicolumn{1}{l|}{ PL } & \multicolumn{2}{l|}{ WI } & \multicolumn{2}{l|}{ D } \\
\cline { 2 - 11 } & S & P & U & B & M & C & PA & OR & PA & ME \\
\hline O & o & o & o & $\times$ & o & $\times$ & o & $\times$ & o & $\times$ \\
\hline MO & $\times$ & $\times$ & $\times$ & o & $\times$ & o & $\times$ & o & $\times$ & o \\
\hline
\end{tabular}

\section{ANALYSIS AND DISCUSSION}

A household's economic situation is more likely related to a construction period of the new houses in the old city of Kabul. As per the study; the building progress was faster after the wars up to 2007 due to the many job opportunities. A survey of the Afghan people in 2015 by The Asia Foundation (TAF) that focused on a full range of issues about country's growth and development shows that the economic situation of households worsened in recent years by $6.9 \%$ in 2012 and $29.7 \%$ in 2015.

The old city's ancient landscape changed after the wars from traditional adobe to the newly industrialized mode. The maximum number of two-story adobe houses in the past turned now to the three and four-story technologically advanced by materials and home functions. The majority of 11 modern houses with three and four stories located in Chindawol quarter compared to the four houses in Asheqanwa Arefan area shown in Fig. 11. This situation means that the Chindawol's historical area is more transformed to a modernized space than Asheqan wa Arefan.

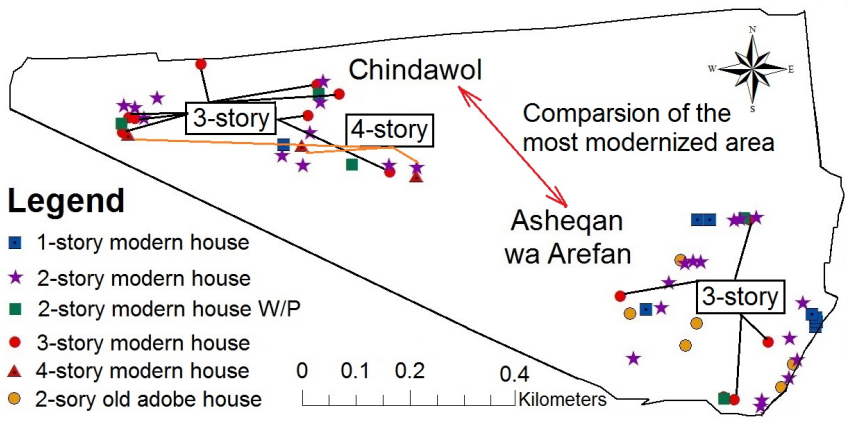

Fig. 11 The location of the most three-story and four-story houses in the study area

The main reason of the on-going modernization started from the temporary repair works permits by district office to the residents stated in chapter 2 page 1. The Fig. 5 in chapter 4 clearly shows a lack of the building regulations, control of the local district office and a proper conservation plan for the old city (Shar-e-Kohna) to keep its historical landscape. According to the study findings, the immediate establishment of the preservation plan is recommended to mitigate the pressure of modernization in the old city of Kabul. Further studies shall be carried out to identify activeactors for the participation.

\section{CONCLUSION}

This study clarifies the transformation of the historical landscape in the old city of Kabul. The primary outcomes are as follow:

1. The maximum number of two stories old houses in the ancient town of Kabul currently has changed to the four stories.

2. The majority of $67 \%$ new houses constructed between 2002 and 2007. 
3. The increasing number of family members and technologically advanced functions were the common reasons for the construction of modern houses.

4. The Chindawol's quarter is more transformed to a modernized area than Asheqan wa Arefan.

\section{REFERENCES}

[1]. Noori Habib and Anna Soave, "Urban Conservation in the Historic Neighbourhoods of Kabul" in Aga Khan Historic Cities Programme: Urban Conservation and Area Development in Afghanistan. Geneva: Aga Khan Trust for Culture, 2007.

[2]. Breshna Zahra, "A Program for the Rehabilitation and Development of Kabul's Historic Center. Development of Kabul," pp.23, 2004.

[3]. RECS International Inc. Yachiyo Engineering Co., Ltd. "Draft Kabul City Master Plan," 4-34, June 2011.

[4]. RECS International Inc. Yachiyo Engineering Co., Ltd. CTI Engineering International Co., Ltd. Sanyu Consultants Inc. "DemographyandSocialDevelopment,"2-3, September 2009.

[5]. RECS International Inc. Yachiyo Engineering Co., Ltd. "Draft Kabul City Master Plan," 4-34, June 2011.

[6]. Aga Khan Historic Cities Programme. "Babur's Garden Rehabilitation Framework." Kabul, Afghanistan, The Aga Khan Trust for Culture, 2004.

[7]. RECS International Inc. Yachiyo Engineering Co., Ltd. CTI Engineering International Co., Ltd. Sanyu Consultants Inc. "DemographyandSocialDevelopment,"2-3, September 2009.

[8]. Mohammad Umar Azizi and Mohammad Akbar Azizi. "A Study on the Transformation of Kabul Old City (Shahre-Kohna)." IJEAS Trans., vol.3, iss.8, pp.51-54, August 2016.

[9]. Nabizada, Toofan. "A study on the spatial structure of houses and open spaces by the analysis of physical improvements and daily activities in the typical residential areas in Kabul City," pp.49 (2013).

[10]. The Asia Foundation. "A survey of the Afghan People," 56, 2015.

[11]. 尾崎 三雄 （文·写真）尾崎鈴子

日本人が見た’ 30 年代のアフガン" 石風社 2003 